\title{
Designing a Framework Based on Problem-Based Learning for CSCL Environments in Order to Enhance 21 st Century Skills
}

\author{
Lydia Koroneou, Fotini Paraskeva, and Aikaterini Alexiou
}

\begin{abstract}
Due to the complexity of the knowledge society and the technology integration, teachers need support in developing their capacity to effectively teach in 21 st century classrooms. In the present study, we advocate the use of a Computer Supported Collaborative Learning Environment orchestrated with the instructional method, Problem-based Learning in order to support collaboration, self-directed learning, critical thinking and problem solving. Aquasiexperimental research was conducted in an academic university department. Qualitative and quantitative data analysis indicate that the integration of the fundamental principles of PBL method in a CSCL context provide an effective framework to enhance 21 st century skills.
\end{abstract}

Index Terms-Problem-based learning, collaboration script, computer supported collaborative learning environment, collaboration, 21 st century skills.

\section{INTRODUCTION}

Due to the complexity of the knowledge society and the technology integration, teachers need support in developing their capacity to teach effectively [1], [2]. One of the greatest challenges is to provide $21^{\text {st }}$ century digital-aged teaching programs focusing on instructional practices and student learning [3]. These programs should emphasize the connection between institutional learning and the 'real' world of teaching. Furthermore, teachers should exemplify a robust level of pedagogical self-efficacy for teaching Science, Technology, Engineering and Mathematics (STEM) [4]. This means that they should follow pedagogically sound teaching practices in order to implement scientific, technological or interdisciplinary projects with inquiry nature.

Towards this direction, we suggest Problem-Based Learning (PBL) as an instructional approach for teachers' training programs. PBL can be viewed as an inquiry-based learning strategy, whichemphasizes on analysis, evaluation, reflection and collaborative group work [5].The fundamental objective of PBL is to equip learners with transferable skills (important $21^{\text {st }}$ skills like collaboration, self-directed learning, critical thinking and problem solving) and knowledge that link school or university to professional life.

\section{A. Literature Review}

The PBL is an instructional method, which uses ill-

Manuscript received October 1, 2012; revised January 4, 2013

The authors are with the Department of Digital Systems, University of Piraeus, Greece (e-mail: lydkor@yahoo.gr, fparaske@unipi.gr, katialex@webmail.unipi.gr). structured problems in order to encourage learners to get involved in the learning process and to develop a set of skills for the 21 st century (such as collaboration, selfdirected learning, critical thinking and problem solving) [6][11]. On this basis, teachers' training programs need to focus on PBL experience for engaging learners in practicalbased experience and reflective practice [4]. In addition, the collaborative nature of PBL indicates the need to utilize Computer Supported Collaborative Learning - CSCL environments [12], [13]. The combination of two ideas (collaborative learning and computer), constitutes a significant tool in the process of restructuring educational challenges [14]. Still, the design of CSCL scripts aimed at configuring the way learners interact [15] embodies a common practice, on the premises that freely co-operating in collaborative learning environments might not go hand in hand with successful interaction. The CSCL scripts do not necessarily contain solely collaborative activities and are defined as a set of guidelines with regard to the manner the members of a team need to interact, co-operate and solve a problem [16].

In the present study, a CSCL scenario (PBL Script) has been designed following the principles of the PBL method for orchestrating the collaborative process and enhancing the $21^{\text {st }}$ century skills.

\section{B. Research Questions}

The research question was: "Can the integration ofPBL principles in a CSCL environment constitutesa frameworkfor enhancing $21^{\text {st }}$ century skills?"

\section{Method}

We conducted a quasi-experimental research whichhas been performed in an academic course titled "Collaborative Learning Environments,"The participants got involved in a case, with the theme"Internet Safety" so as to assist learners in comprehending the dangers that exist online and restrict contemporary threats, namelyScareware, Spyware, Hoax, Grooming etc.

\section{CSCL Environment}

The CSCL environment consists of a system for synchronous and asynchronous communication and collaboration (Google Wave) and a course management system (Moodle) forup keeping the educational content.

\section{PBL METHOD}

\section{A. Specifications for the PBL Script}

The PBL script is consistent with the CSCL Scripts 
design specifications [17]. These specifications provide detailed descriptions of the components (participants, roles, teams, resources and activities), constituting the PBL Script, which can be employed as reference for future implementation.

\section{B. Ill-Structured Problem}

The PBL Script is based on the principles of the PBL instructional method, which commences with an illstructured problem, serving as the vehicle for the learning process [6], [18], [19]. An ill-structured problem has, thereof, been designed.To be more specific, the eligible teachers were invited to create an "Internet Safety" script. As stated in Barrows' theory, PBL uses ill-structured problems, as a stimulus for learning [6], [19].

\section{Components of the PBL Script}

Participants: In total, 27 prospective ICT teachers participated in thePBL Script. The participants who voluntarily signed up and constituted the experimental group.

Roles Of Students: Selected learning issues were tackled by small groups designated within larger ones [20]. However,within the context of our study, small groups have been used, in which each individual had a selected role (project leader, facilitator, recorder, team member) in order to tackle learning issues.

Role Of Facilitator:Accounting on PBL theory, the educator guides rather than directs students' learning (facilitator) [6]. In our study, the role of the facilitator in the learning process is based on the "autonomous mode" [21], [22].

Groups: Barrows [23] has indicated that a small group more than 8 people cannot work properly, because the differences of people can affect the functioning in the group. For this study the number of the members within each group, was 4 , given that they were collaborating in a CSCL environment [9]. PBL relies heavily on group dynamics for its success; however it is not effective when there is lack of direct personal contact [24]. Hence, in this study, the formation of the groups relied on their learning styles [25].

Resources: Anill-structured problem, accompanied by information that do not reveal the solution to the problem, but create a context that can motivate learners' thought [26]. In consequence, within the current study, resources, relevant to an ill-structured problem, have been provided to learners. These resources have been uploaded on Moodle and were made available throughout the process.

Activities: The experimental procedure follows the PBL Script process, consisting of 7 phases. Based on Barrow's \&Kelson model [27], the PBL Script phases have been designed to create a learner-centered environment and enhance 21 st century skills (Table. I). Analytically:

Climate Setting:The primary aim of the initial phase is focused on learners' preparation, with regard to the learning process schedule, theirassignment to teams, the clarification of their roles within their teams and their registration to the CSCL environment (Google Wave and Moodle).

Phase 1: Includes studying the ill-structured problem via resources uploaded onto Moodle.

Phase 2: Encompasses teamwork (Google Wave) in order to comprehend the suggested solutions to the illstructured problem.

Phase 3: Refers to individual study and the development of an individual proposal as regards the solution of the illstructured problem.

Phase 4: Encompasses teamwork (Google Wave) to facilitate the synthesis of a team proposal, based on existent knowledge, for solving the ill-structured problem.

Phase 5: Includes information sharing and the study of the team ill-structured problem solution proposals.

Phase 6: Comprises collaboration among learners (Google Wave) to provide mutual feedback between 2 teams with regard to the team solution proposals for the illstructured problem.

Phase 7: Includes learners' reflection on the learning process by virtue of completing 2 rubrics.

Assessment: Formal assessment in PBL is based on learners' skills, and the extent and depth of knowledge associated with the ill-structured problem [6]. The assessment methods used in our study were those of authentic assessment (self and peer assessment), focusing on skills (collaboration, self-directed learning, critical thinking) that derive from the learning process.

TABLE I: EXPERIMENTAL PROCEDURE: THE PROPOSED FRAMEWORK FOR THE INTEGRATION OF THE PBL SCRIPT INTO A CSCL ENVIRONMENT

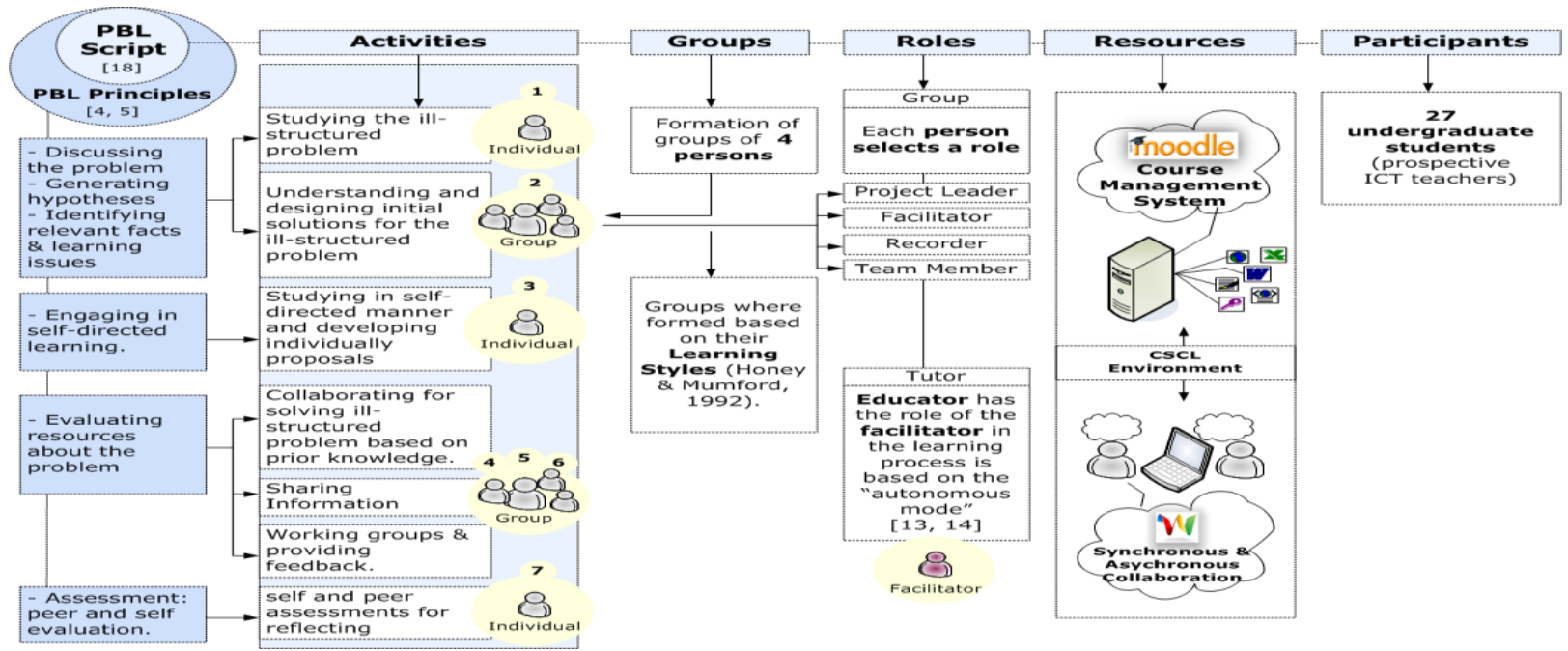




\section{CONCLUSIONS}

\section{A. Discussion}

The data analysis was performed by use of the qualitative andquantitative method. Specifically, self and peer assessment rubrics, reflecting the PBL process and includingcertain indicators for collaboration (i.e.Achieving team objectives was my principal expectation, I exemplified responsibility and commitment to the members of my team), self-directed learning (i.e. I defined my learning objectives as regards the problem, the study of various, up to date, bibliographical references has been demonstrated) and critical thinking skills (i.e. I am capable of identifying significant information concerning the problem, I am capable of identifying learning issues in need of further research). The rubrics are based on a study [28], which is based on a PBL environment assessment system, classifying the skills developed by students throughout the learning process.

The overall results reveal learners' active participation in the problem-solving process of the ill-structured problem and the reinforcement of the $21^{\text {st }}$ century skills (collaboration, self-directed learning and critical thinking skills), as depicted in the assessment process.

\section{B. Future Work}

Through this study, we accentuate the importance of using innovative technologies, such as CSCL environments, combined with well-structured instructional methods, such as PBL, in teacher training settings. The PBL Script is the outcome of an attempt to model the basic principles of the PBL method, in order to enhance the $21^{\text {st }}$ century skills. On this basis, we propose this Script as a frameworkfor teacher training programs, ad hoc we propose the PBL Script for further implementation and evaluationespecially in STEM programs.

\section{REFERENCES}

[1] H. Khan, K. Maull, and T. Sumner, "Curriculum Overlay Model for Embedding Digital Resources," in Proc. the Joint Conference on Digital Libraries, New York: ACM, 2008, pp.74-83.

[2] A. Walker, M. B. Robertshaw, and M, Recker, "Problem-Based Design: A Technology-Oriented Teacher Professional Development Model," presented at the American Educational Research Association Annual Conference, Denver, Co, April 2010.

[3] H. Borko, "Professional Development and Teacher Learning: Mapping the Terrain," Educational Researcher, vol. 33, no. 8, pp. 315, Nov. 2004

[4] L. Brears, W. MacIntyre, and G. O'Sullivan, "Preparing Teachers for the 21st Century Using PBL as an Integrating Strategy in Science and Technology Education," Design and Technology Education: An International Journal, vol. 16, no. 1, pp. 36-46, 2011.

[5] A. Gorransson, "Words and Action in Vocational Training," in M. Osborne, M. Houston, and N. Toman (Eds.), The Pedagogy of LifeLong Learning: Understanding Effective Teaching and Learning in Diverse Contexts, London.

[6] H. S. Barrows, "Problem-based learning in medicine and beyond: A brief overview," New Directions for Teaching and Learning, no. 68, pp. 3-12, Winter 1996.

[7] M. C. Lohman and M. Finkelstein, "Designing Cases for ProblemBased Learning to Foster Problem Solving Skill," Euro J Dent Educ. vol. 6, no. 3, pp. 121-127, 2002.

[8] M. Savin-Baden, Problem-Based Learning in Higher Education: Untold Stories, Buckingham: Open University Press/SRHE, 2000.

[9] M. Savin-Baden, "Challenging PBL Models and Perspectives," in E. D. Graaff and A. Kolmos (Eds.), Management of Change Implementation of Problem-Based and Project-Based Learning in Engineering, SENSE Publisher, Rotterdam, 2007, pp. 9-30.

[10] K. A. Elliott and G.E. Kennedy, "Using Educational Technologies to Understand How Learners Solve Problems," in Proc. the 23rd annual ascilite conference: Who's learning? Whose technology? ascilite 2006, The University of Sydney.

[11] Y. L. Visser, "Effects of Problem-Based and Lecture-Based Instructional Strategies on Problem Solving Performance and Learner Attitudes in a High-School Genetics Class," presented at the 2002 Annual Meeting of the American Educational Research Association, New Orleans, LA

[12] J. Lu, S. P. Lajoie, and J. Wiseman, "Scaffolding Problem-Based Learning with CSCL Tools," Computer-Supported Collaborative Learning, vol. 5, no. 3, pp. 283-298, 2010

[13] C. E. Hmelo-Silver, "Collaborative Ways of Knowing: Issues in Facilitation," in Proc. CSCL, Boulder, USA, 2002, pp. 199-208.

[14] E. Lehtinen, K. Hakkarainen, L. Lipponen, M. Rahikainen, and H. Muukkonen, Computer Supported Collaborative Learning: A Review of Research and Development, The J. H. G. I. Giesbers Reports on Education, 10, Department of Educational Sciences University of Nijmegen, University on Nijmege, 1999.

[15] P. Dillenbourg and P. Jermann, "Designing Integrative Scripts," in F. Fischer, I. Kollar, H. Mandl, and J. Haake (Eds.), Scripting Computer-Supported Collaborative Learning: Cognitive, Computational and Educational Perspectives, New York: Springer pp. 275-301, 2006.

[16] A. M. O'Donnell and D. F. Dansereau, "Scripted Cooperation in Student Dyads: A Method for Analyzing and Enhancing Academic Learning and Performance," in R. Hertz-Lazarowitz and N. Miller (Eds.), Interaction in Cooperative Groups: The Theoretical Anatomy of Group Learning, New York, NY, US: Cambridge University Press, pp. 120-141, 1992.

[17] L. Kobbe, A. Weinberger, P. Dillenbourg, A. Harrer, R. Hämäläinen, P. Häkkinen, and F. Fischer, "Specifying Computer-Supported Collaboration Scripts," International Journal of Computer Supported Learning, vol. 2, no. 2-3, pp. 211-224, 2007.

[18] J. R. Savery, "Overview of Problem-Based Learning: Definitions and Distinctions," The Interdisciplinary Journal of Problem-based Learning, vol. 1, no. 1, pp. 9-20, 2006.

[19] H. S. Barrows, "Foreword," in D. H. Evensen and C. E. Hmelo (Eds.), Problem Based Learning: A Research Perspective on Learning Interactions, Mahwah, NJ: Lawrence Erlbaum Associates, Inc. 2000.

[20] H. S. Barrows, A. Myers, R. G. Williams, and E. J. Moticka, "Large Group Problem-Based Learning: A Possible Solution for the 2 Sigma Problem," Medical Teacher, vol. 8, no. 4, pp. 325-331, 1986.

[21] J. Heron, The Facilitator's Handbook, London: Kogan, 1989.

[22] J. Heron, Group Facilitation, London: Kogan, 1993.

[23] H. S. Barrows, The Tutorial Process, Springfield, IL: Southern Illinois University School of Medicine, $2^{\text {nd }}$ ed, 1992.

[24] P. Sancho, P. Moreno-Ger, R. Fuentes-Fernández, and B. FernándezManjón, "Adaptive Role Playing Games: An Immersive Approach for Problem Based Learning," Educational Technology and Society, vol. 12, no. 4, pp. 110-124, 2009.

[25] P. Honey and A. Mumford, The Manual of Learning Styles (3d Ed), Maidenhead Berkshire: Published \& Distributed, 1992

[26] A. J. Amador, L. Miles, and C. B. Peters, The Practice of ProblemBased Learning: AGuide to Implementing PBL in the College Classroom, Bolton, Mass.: Anker Pub. Co., 2006.

[27] H. S. Barrows and A. M. Kelson. Problem-Based Learning: A Total Approach to Education, Southern Illinois: University School of Medicine, 1993.

[28] L. L. Elizondo-Montemayor, "Formative and Summative Assessment of the Problem-Based Learning Tutorial Session Using a CriterionReferenced System," Journal of the International Association of Medical Science Educators, vol. 14, no. 1, pp. 8-14, 2004.

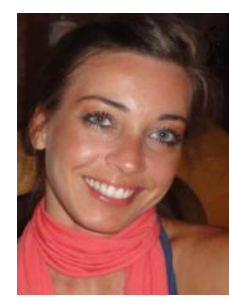

learning.
Lydia Koroneouisa is a computer science teacher at a private nursery and primary schools. She holds a bachelor degree in Applied Informatics in Management and Finance from the Technological Educational Institute of Messolonghi (Greece) and a Master of Science in E-learning from University of Piraeus (Greece). Her research interests include computer supported collaborative learning environments, learning management systems and instructional methods such as problem-based 


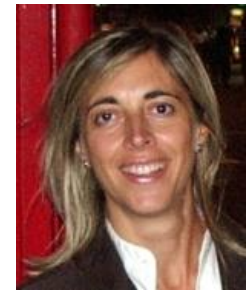

Fotini Paraskeva is an assistant professor at the Department of Digital Systems, of the University of Piraeus (Greece). She holds a Bachelordegree inEducation from National and Kapodistrian University of Athens (NKUoA), Greece. She obtained her Ph.D. in Educational Psychology from NKUoA in the domain of Learning with Technology. Her research interest is broadly of study learning with media and I.C.T. in educational settings, with particular emphasis on cognitive, emotional and social aspects of learning. Her current work also involves specific applied research design of the use of I.C.T. in rich training and work environments, such as professional development in I.T. context, based on quantitative and qualitative methodologies.

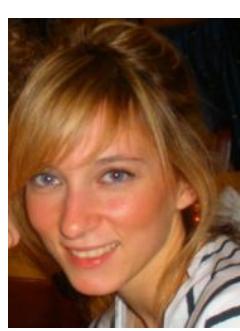

Aikaterini Alexiou is a $\mathrm{PhD}$ candidate in the Department of Digital Systems of University of Piraeus (Greece), in the research Area of Technology-Enhanced Learning. She holds a Master of Science in E-learning from University of Piraeus. Her research interests include ePortfolios for developing self-regulated learning skills, computer supported collaborative learning environments and adaptive systems based on learning styles. She has many years of experience in teaching and she works schools. as a Computer Science Teacher at public primary 